\title{
The ribosome inhibiting protein riproximin shows antineoplastic activity in experimental pancreatic cancer liver metastasis
}

\author{
AHMED MURTAJA $^{1,2}$, ERGÜL EYOL ${ }^{1,3}$, JIANG XIAOQI $^{4}$, MARTIN R. BERGER $^{1}$ and HASSAN ADWAN ${ }^{5}$ \\ ${ }^{1}$ German Cancer Research Center, Toxicology and Chemotherapy Unit, D-69120 Heidelberg; \\ ${ }^{2}$ Klinikum der Stadt Ludwigshafen, D-67063 Ludwigshafen, Germany; ${ }^{3}$ Faculty of Pharmacy, \\ University of Inonu, 44280 Malatya, Turkey; ${ }^{4}$ German Cancer Research Center, Division of Biostatistics, \\ D-69120 Heidelberg, Germany; ${ }^{5}$ The German University in Cairo-GUC, New Cairo 11835, Egypt
}

Received April 6, 2017; Accepted August 4, 2017

DOI: $10.3892 / \mathrm{ol} .2017 .7526$

\begin{abstract}
Pancreatic ductal adenocarcinoma (PDAC) has one of the poorest prognoses of all malignancy types. To improve the survival of patients with PDAC, the development of novel anticancer agents is warranted. Riproximin (Rpx) is a newly identified plant lectin, which was isolated from Ximenia americana. The ribosome inactivating protein of type II exhibits potent anticancer activity as recently demonstrated. The rat PDAC cell line ASML was used for in vitro and in vivo studies. The antiproliferative effect of Rpx was assessed using an MTT assay. The modulation of proteins involved in apoptosis was evaluated using western blotting. Tumor-bearing nude rats were treated with Rpx, gemcitabine (GEM) or dinaline (DIN) as single agents, or a combination of Rpx with GEM, or DIN. Rpx was administered intraperitoneally at doses of 1.7-5.4 $\mu \mathrm{g} / \mathrm{kg}$, three times/week, GEM was administered intravenously $(50 \mathrm{mg} / \mathrm{kg} /$ week) and DIN perorally (10 mg/kg, 5 times/week). Rpx inhibited ASML cell proliferation at $\mathrm{IC}_{50}$-values of $0.8-172 \mathrm{pM}$, caused apoptosis and reduced tumor growth significantly by $90 \%(\mathrm{P}<0.05)$. The survival rate of rats was significantly increased (21.8 days for Rpx treated vs. 17.6 days for control rats; $\mathrm{P}=0.05$ ). Higher doses of Rpx caused no further reduction in tumor size when compared with the low dose of Rpx or a combination of Rpx with GEM, or DIN. The standard drug GEM alone was less effective compared with Rpx. In addition, DIN was ineffective, and in combination, reduced the activity of Rpx. These results suggest that Rpx has an evident potential for use in pancreatic cancer treatment. Further experiments are required in order to elucidate its affinity for certain cancer cells and to optimize the combination therapy with other antineoplastic agents.
\end{abstract}

Correspondence to: Professor Hassan Adwan, The German University in Cairo-GUC, Main Entrance Al Tagamoa Al Khames, New Cairo 11835, Egypt

E-mail: hassan.adwan@guc.edu.eg

Key words: pancreatic cancer treatment, ASML cell line, lectin, Ximenia americana

\section{Introduction}

Pancreatic ductal adenocarcinoma (PDAC) has one of the worst prognoses of all malignancies worldwide (1). The incidence of PDAC continues to increase and ranks as fourth cause of cancer related mortality. Despite radical surgical intervention (R0 resection) and chemo-radiation, the survival for all stages at 5 years is about $6 \%$ in Europe and the United States $(2,3)$.

The most effective single chemotherapy intervention against advanced PDAC has been achieved with gemcitabine (GEM). GEM has significantly improved the median overall survival of PDAC patients by 1.2 months over patients treated with 5 -fluorouracil and became the reference drug for this disease (4). 5-Fluorouracil has also some clinical activity against advanced PDACA with a median overall survival of 4.4 months (2).

However, many trials with other drugs in combination with GEM were investigated in the last decade; a combination of GEM and oxaliplatin has shown a benefit in a phase II study (5). In addition, a recent randomized trial with FOLFIRINOX has enhanced the median overall survival, when compared with GEM (11.1 months vs. 6.8 months respectively) (4). This combination was even superior to the recently published combination of gemcitabine with nab-paclitaxel, which resulted in a median survival time of 8.5 months vs. 6.7 months following gemcitabine alone (6).

The efficacy of chemo-radiation in advanced PDAC has been evaluated in many randomised trials. It was shown that chemo-radiation is superior to best supportive care and to radiotherapy alone, but more toxic and equally effective in comparison to chemotherapy alone (7).

Altogether, the relatively poor efficacy of chemotherapy and chemo-radiation against this devastating disease indicates that the development of new therapeutic strategies is a crucial step to improve the survival of advanced PDAC. This includes modification of established therapies and testing of new substances.

Ribosome inhibiting proteins are a group of highly potent plant lectins, which can kill tumor cells at nano- to picomolar concentrations. Certain members of this group like viscumin, abrin and ricin have been analysed for their anticancer activities in several clinical and preclinical trials $(8,9)$. More than 
4 decades ago, Abrin and Ricin have been found to be more toxic to tumor than to normal cells (10). Aviscumin, which was produced in Escherichia coli as a recombinant lectin, has shown immunomodulatory and cytotoxic activities. In clinical phase I/II studies, it achieved disease stabilization in some cases (11). Rips of type II consist of two protein chains. The A-chain is cytotoxic due to its de-purinating activity in ribosomes, leading to a stop in protein synthesis. The B-chain shows affinity for certain sugar moieties, which confer its lectin binding. The ribosome inactivating protein (RIP) A-chain has been used to construct toxic antibody conjugates targeting cancer specific antigens (9). For example, the immunotoxin Combotox consists of the ricin A-chain coupled to an antibody directed against cell surface antigens CD19 and CD22 and has been investigated in a phase I study as a candidate for treatment of children with refractory leukaemia (8).

Riproximin is a new plant lectin, which was isolated from the plant Ximenia americana and identified as the active component of a powdered plant material used in African traditional medicine. Riproximin was classified as a RIP of type II $(12,13)$. In addition to the conventional mode of action, Rpx was found to induce the unfolded protein response, a cellular mechanism activated in response to endoplasmic reticulum stress. Apoptosis was induced by concentrations at which translation of UPR-related genes occurred, despite concomitant ribosomal depurination (14). This study was set up to explore the antineoplastic efficacy of Rpx in PDAC. The ASML rat PDAC cell line and clones derived from this line were used as model for in vivo and in vitro experiments on the activity of Rpx. Here, we report on the anticancer activity of Rpx against ASML cells in comparison to GEM as standard compound.

\section{Materials and methods}

Cell culture. The pancreatic cancer cell line ASML and its clones 2, 5 and 10 were used. The cells were maintained in an incubator under standard culture conditions at $37^{\circ} \mathrm{C}$ in humidified air with $5 \% \mathrm{CO}_{2}$. For keeping the cells in logarithmic growth, they were propagated 1-3 times per week depending on their growth rate.

MTT assay. For determining the proliferation rates and the effect of riproximin on the ASML cells, they were seeded at densities of $1 \times 10^{3}-10 \times 10^{3}$ cells/ml (100 $\mu 1$ medium per well) into 96 well-plates (flat bottom; Becton Dickinson, Heidelberg, Germany).Subsequent experiments on the sensitivity to Rpx were performed with $2 \times 10^{3}-3 \times 10^{3}$ cells per well, which were treated with different concentrations of Rpx and thereafter grown for periods of 24, 48, 72 and $96 \mathrm{~h}$. After these periods, $10 \mu \mathrm{l}$ MTT [3-(4.5-dimethylthiazol-2-yl)-2.5-diphenyl tetrazolium bromide; Serva Electrophoresis GmbH, Heidelberg, Germany] solution (10 $\mathrm{mg} / \mathrm{ml}$ ) was added and following an incubation period of $3 \mathrm{~h}$ at $37^{\circ} \mathrm{C}$, the medium was discarded and the cells were lysed by adding $200 \mu \mathrm{l}$ per well acidified 2-propanol $(0.04 \mathrm{~N} \mathrm{HCl})$. After all formazan crystals had been carefully dissolved, the absorption was measured at $540 \mathrm{~nm}$ (reference filter of $690 \mathrm{~nm}$ ) in an automated microtiter plate spectrophotometer (Anthos Mikrosysteme, Krefeld, Germany). The absorption of exposed cells was given in percent of untreated control cells.
Reagents and chemicals. Gemcitabine (GEM) was provided by (Eli Lilly, Bad Homburg, Germany) at a quality suited for clinical use. Before each experiment, the antimetabolite was dissolved and diluted in sterile $0.9 \%$ saline to appropriate concentrations. Riproximin ( $\mathrm{Rpx}$ ) was purified from Ximenia americana kernels according to a described method, Bayer et al (15). Rpx was diluted in sterile physiological saline for the in vitro and in vivo experiments. The ASML cells were exposed to Rpx at concentrations ranging from 0.1 to $333 \mathrm{pM}$. The cell survival was controlled by MTT-test after 24, 48, 72 and 96 h. Dinaline [4-amino-N-(2'-aminophenyl) benzamide, Din] was supplied by Goedecke AG (Freiburg, Germany) in a purity required for clinical use. For administration to animals, the compound was suspended in $0.8 \%$ Methocel (Nordmann-Rasmann, Hamburg, Germany) immediately before application.

Animals. All animal experiments were performed in accordance with the Regierungspräsidium Karlsruhe (Germany), which as Institutional Animal Care and Use Committee (IACUC) approved the animal ethics of this study for the German Cancer Research Center (DKFZ), Heidelberg. According to this permit, the animals were randomly allocated to treatment and control groups and they were humanely euthanized after four weeks at the end of the experiment or when they met certain clinical criteria indicating a moribund status. The criteria used to determine when the animals should be humanely euthanized included a weight loss of more than $10 \%$, pale skin color indicating anemia, icterus, as well as pain or reduced general conditions as indicated by reluctance to move, abnormal posturing, and decreased appetite. All animals were daily monitored for their condition. For sacrifice, a narcosis with isofluorane followed by $\mathrm{CO}_{2}$ was used. Steps taken to minimize suffering of the animals, included analgesics (metamizole) administered post-surgically for up to three days and anesthetics (isoflurane) for inhalation anesthesia during surgery. As appropriate, the German guidelines, which are similar to the ARRIVE guidelines for reporting animal studies were followed.

Male RNU rats were used for the in vivo experiments. They were obtained from Charles River (Sulzfeld, Germany) at an age of 5-7 weeks and a corresponding body weight of 120-160 g. They were kept under specific pathogen free (SPF) conditions in Macrolon-III-cages of a ventilated rack (Ventirock, UNO Roestvaststaal B.V., Zevenaar, The Netherlands) providing a 50 -fold exchange of filtered air per hour as well as positive air pressure inside the cages. Constant room temperature $\left(22 \pm 1^{\circ} \mathrm{C}\right)$, air humidity $(50 \pm 10 \%)$ and dark-light-rhythm (12 h) were maintained throughout. The animals had free access to autoclaved water and standard laboratory diet. An acclimatisation period of 7 days was adhered to before starting any experiments.

Tumor cell transplantation. The procedure used was as described previously (16): In short, logarithmically growing ASML GFP-LUC cells were trypsinized and suspended ( $2 \times 10^{6}$ cells) in $0.25 \mathrm{ml}$ PBS (phosphate-buffered saline without calcium and magnesium ions) and $0.15 \mathrm{ml}$ matrigel (extract of the Engelbreth-Holm-Swarm-mouse tumor; Biomatrix EHS solution; Serva Electrophoresis $\mathrm{GmbH}$ ). This suspension was stored on ice until injection. For tumor cell transplantation, the 
Table I. Experimental design for transplantation and treatment of ASML PDAC cells in nude rats.

\begin{tabular}{|c|c|c|c|c|c|c|c|}
\hline Trial & $\begin{array}{c}\text { Group } \\
\text { no. }\end{array}$ & $\begin{array}{c}\text { Animal } \\
\text { no. }\end{array}$ & Treatment & Route & Dose & Regimen & Total dose \\
\hline \multirow[t]{3}{*}{1} & $1 \mathrm{a}$ & 3 & Control 1 & - & - & - & - \\
\hline & $1 b$ & 3 & $\mathrm{Rpx}^{\mathrm{a}}$ & p.o. & $3.4 \mu \mathrm{g} / \mathrm{kg}$ & Days 1-3 for one week & $10.2 \mu \mathrm{g} / \mathrm{kg}$ \\
\hline & $1 \mathrm{c}$ & 3 & Rpx & i.v. & $3.4 \mu \mathrm{g} / \mathrm{kg}$ & Days 1-3 for one week & $10.2 \mu \mathrm{g} / \mathrm{kg}$ \\
\hline \multirow[t]{5}{*}{2} & $2 \mathrm{a}$ & 8 & Control 2 & - & - & - & - \\
\hline & $2 b$ & 5 & Rpx & i.v. & $1.7 \mu \mathrm{g} / \mathrm{kg}$ & $3 x$ daily every 2 nd day for 2 weeks & $35.7 \mu \mathrm{g} / \mathrm{kg}$ \\
\hline & $2 \mathrm{c}$ & 5 & Dinaline & p.o. & $10 \mathrm{mg} / \mathrm{kg}$ & $1 \mathrm{x}$ daily for 10 days & $100 \mathrm{mg} / \mathrm{kg}$ \\
\hline & $2 d$ & 5 & $\mathrm{Rpx}+$ & i.v+ & $1.7 \mu \mathrm{g} / \mathrm{kg}+$ & $3 x$ daily every 2 nd day for 2 weeks + & $35.7 \mu \mathrm{g} / \mathrm{kg}+$ \\
\hline & & & Din & p.o. & $5 \mathrm{mg} / \mathrm{kg}$ & $1 \mathrm{x}$ daily for 10 days & $100 \mathrm{mg} / \mathrm{kg}$ \\
\hline \multirow[t]{7}{*}{3} & $3 a$ & 5 & Control 3 & - & - & - & - \\
\hline & $3 b$ & 5 & $\mathrm{Rpx}$ & i.p & $5.1 \mu \mathrm{g} / \mathrm{kg}$ & Every 2 nd day for 20 days & $51 \mu \mathrm{g} / \mathrm{kg}$ \\
\hline & $3 c$ & 5 & Rpx & i.p. & $3.4 \mu \mathrm{g} / \mathrm{kg}$ & Every 2 nd day for 20 days & $34 \mu \mathrm{g} / \mathrm{kg}$ \\
\hline & $3 d$ & 5 & $\mathrm{Rpx}$ & i.p & $1.7 \mu \mathrm{g} / \mathrm{kg}$ & Every 2 nd day for 20 days & $17 \mu \mathrm{g} / \mathrm{kg}$ \\
\hline & $3 e$ & 5 & $\mathrm{GEM}^{\mathrm{b}}$ & i.p. & $50 \mathrm{mg} / \mathrm{kg}$ & $1 \mathrm{x}$ weekly for 2 weeks & $100 \mathrm{mg} / \mathrm{kg}$ \\
\hline & $3 f$ & 5 & $\mathrm{Rpx}+$ & i.p+ & $1.7 \mu \mathrm{g} / \mathrm{kg}+$ & Every 2 nd day for 20 days+ & $17 \mu \mathrm{g} / \mathrm{kg}+$ \\
\hline & & & GEM & i.p. & $50 \mathrm{mg} / \mathrm{kg}$ & 1x weekly for 2 weeks & $100 \mathrm{mg} / \mathrm{kg}$ \\
\hline
\end{tabular}

ariproximin, ${ }^{\mathrm{b}}$ gemcitabine.

rats were anaesthetized with isoflurane at 1.5 vol\% together with $0.5 \mathrm{l} / \mathrm{min}$ oxygen and $1 \mathrm{l} / \mathrm{min}$ nitrous oxide.

After a median laparotomy, the caecum was exteriorized onto a compress moistened with sterile physiological saline and a mesocolic vein was isolated from mesenteric fat. Under microscopic control the tumor cell suspension was injected into this vessel with a 28-gauge needle.

Thereafter the vessel was compressed with two cotton swabs for a period of 1-2 min to prevent bleeding; the caecum was moved back into the abdomen; the musculature was sutured (4-0 vicryl, Ethicon GmbH, Norderstedt, Germany) and the skin was closed with metal clips.

In vivo imaging. Live animal bioluminescence imaging was performed using the IVIS100 imaging system (Xenogen Corp., Alamede, CA, USA). Prior to imaging, the animals were injected intraperitoneally with the substrate D-Luciferin (Synchem Corp. Elk Grove Village, IL, USA) at a dose of $10 \mathrm{mg} / \mathrm{animal}$ and anesthetized with isoflurane/oxygen via the XGI-8 Anesthesia System (Xenogen Corp.), The images obtained by the IVIS 100 camera were subsequently analyzed using the Living Image v2.5 software provided by Xenogen Corp.

In vivo experiments. For determining the effect of riproximin in a rat liver metastasis model, the ASML-rat model was used, as described before (see ASML model in reference 16). Tumor-bearing rats were treated per-orally, intra-peritoneally or intravenously with different concentration of riproximin, gemcitabine, or dinaline. To observe the tumor development, the animals were imaged according to the previously described protocol (see in vivo imaging). Three to four weeks later, the experiment was terminated, the animals euthanized, the liver of the animals was removed, weighed, and kept at $-80^{\circ} \mathrm{C}$ until further analysis.
Single and combined drug exposure. The design of treating ASML cells growing in nude rats is given in Table I. The dosages used for treatment were based on earlier studies.

By various application forms (i.v., p.o., i.p.), riproximin was administered twice weekly at a dose range of 1.7 to $5.1 \mu \mathrm{g} / \mathrm{kg}$ to RNU rats. GEM and DIN were administered to animals either intravenously at a dose of $50 \mathrm{mg} / \mathrm{kg}$ weekly or perorally at a dose of $10 \mathrm{mg} / \mathrm{kg}, 5$ times weekly.

Cell lysis for western blot analysis. Cell pellets from the ASML cell line were collected and re-suspended in buffer containing $0.1 \mathrm{M} \mathrm{NaCl}, 10 \mathrm{mM}$ Tris- $\mathrm{HCl}$ and $1 \mathrm{mM}$ ethylenediaminetetraacetic acid (EDTA). Thereafter, an equal quantity of lysis buffer (100 mM Tris-HCl, 4\% sodium dodecyl sulfate (SDS), $20 \%$ glycerol) was added. Both buffers were supplemented with Complete TM protease inhibitor mixture (Roche Molecular Biochemicals, Mannheim, Germany) as recommended by the manufacturer. The lysis buffer was additionally supplemented with dithiotreitol (DTT) to a final concentration of $200 \mathrm{mM}$. Lysates were boiled for $10 \mathrm{~min}$ at $99^{\circ} \mathrm{C}$ in a Thermomixer (Eppendorf, Hamburg, Germany) at a mixing frequency of $500 \mathrm{rpm}$ and thereafter centrifuged at $10,600 \mathrm{x} \mathrm{g}$ for $10 \mathrm{~min}$ at $4^{\circ} \mathrm{C}$. The protein concentration in a portion of each sample, lysed without DTT, was determined using the Pierce BCA Protein Assay kit (Pierce Biotechnology, Rockford, IL, USA) according to the recommendations of the manufacturer.

Immunoblot detection. Equal amounts of protein (20-50 $\mu \mathrm{g}$ from whole cell lysates) were loaded onto a 4-12\% Bis-Tris gel (Invitrogen, Karlsruhe, Germany), and separated by electrophoresis under reducing and denaturing conditions. Proteins were then transferred to a PVDF membrane using the XCell II blot module (Invitrogen). For membrane blocking and antibody dilution, milk powder (5\% in TBS-T, $0.1 \%$ Tween 20 ) was used. The 
membrane was blocked for $1 \mathrm{~h}$ at RT followed by incubation with the primary antibody at $4^{\circ} \mathrm{C}$ overnight. Antibodies against caspases 3, 8, and 9, ATF3 and ERK2 were obtained from Santa Cruz (Heidelberg, Germany). After washing with TBS-T (3 times for $10 \mathrm{~min}$ ), the blot membrane was incubated with the appropriate secondary antibody conjugated to horseradish peroxidase at RT for $1 \mathrm{~h}$, followed by four washing steps with TBS-T (10 min each). Visualization of the antibody complexes was done by incubating the membrane with a chemiluminescent peroxidase substrate and exposing it to X-ray films. Light signals were quantified by the Quantity One software (Biorad, Munich, Germany). Intensities of target protein bands were normalized to ERK2 as the loading control.

Statistical analysis. The cell survival fractions were calculated as the ratio of MTT-absorptions from treated and control cells. The results of multiple measurements were given as mean with corresponding standard deviation. Response was normalized by dividing by mean control response. The 4-parameter log-logistic model was fitted to individual normalized response values, constraining the lower limit to be non-negative. Calculations were performed using $\mathrm{R}$ version 3.0.1 (http://www.R-project.org) and R-Package 'drc' version 2.3-96 for dose-response analysis.

\section{Results}

Rpx antineoplastic activity. The cytotoxic activity of Rpx was assessed in ASML rat PDAC cells as well as in the clones 2, 5, and 10, which are derived from ASML.

The mother cell line and its clones differ by morphologic and proliferative properties as indicated by tumor cell number doubling times of $34 \mathrm{~h}$ for ASML cells, $18 \mathrm{~h}$ for clone $2,12 \mathrm{~h}$ for clone 5 , and $36 \mathrm{~h}$ for clone 10 . With respect to morphologic criteria, cells of the mother cell line ASML have a mostly rounded form. They show coherent and homogenous growth. The cells of clone 2 are relatively large with a central small nucleus. They grow coherent and homogenous in an epithelial mode with formation of ductal like structures. The cells of clone 5 are either large and partly polygonal with a polar nucleus, or small and round. They are mostly coherent to each other. Clone 10 cells are mainly small and round. During the log phase of their growth, a part of these cells show a spindle-cell like form. Spontaneous apoptosis is observed during this phase.

In the original cell line, Rpx caused $50 \%$ growth inhibition (IC 50) at a concentration of $65 \mathrm{pM}$ after $24 \mathrm{~h}$. The IC50 decreased 18 fold over the subsequent three days of observation, from $10 \mathrm{pM}$ (48 h) to $8 \mathrm{pm}$ (72 h) and 4 pM (96 h), Fig. 1A and Table II. The ASML clone 2 was more sensitive than the ASML-mother cells after 24 h (IC50 33 pM), but showed a distinctly lower reduction in IC 50 values during the subsequent three days of observation. These dropped only 3 fold to 29 pM (48 h), 17 pM (72 h), and 11 pM (96 h, Fig. 1B). In addition, clone 2 cells were stimulated in growth by maximally $8 \%$ in response to the lowest dose of Rpx $(0.1 \mathrm{pM})$.

Clone 5 was most sensitive to Rpx as shown by IC50 values ranging from $10 \mathrm{pM}(24 \mathrm{~h})$ to $1 \mathrm{pM}(96 \mathrm{~h})$, with a 13 fold reduction during the observation time (Fig. 1C).

In addition, there was an initial slight stimulation of ASML-clone 2 cells at the low concentrations of Rpx $(<1 \mathrm{pM})$.
Table II. Efficacy of riproximin in ASML cell lines: IC50 values and $95 \%$ confidence limits.

\begin{tabular}{|c|c|c|c|c|}
\hline Cell line & Time & $\begin{array}{l}\text { IC } \\
50^{\mathrm{a}}\end{array}$ & $\begin{array}{c}\text { Lower } \\
95 \% \\
\text { confidence } \\
\text { limit }^{\mathrm{a}}\end{array}$ & $\begin{array}{c}\text { Upper } \\
95 \% \\
\text { confidence } \\
\text { limit }^{\mathrm{a}}\end{array}$ \\
\hline \multirow[t]{4}{*}{ ASML } & $24 \mathrm{~h}$ & 64,5 & 38,7 & 107,4 \\
\hline & $48 \mathrm{~h}$ & 10,1 & 7,0 & 14,8 \\
\hline & $72 \mathrm{~h}$ & 7,6 & 6,6 & 8,8 \\
\hline & $96 \mathrm{~h}$ & 3,6 & 3,0 & 4,3 \\
\hline \multirow[t]{4}{*}{ Clone 2} & $24 \mathrm{~h}$ & 32,5 & 17,0 & 62,1 \\
\hline & $48 \mathrm{~h}$ & 28,7 & 21,2 & 38,8 \\
\hline & $72 \mathrm{~h}$ & 17,3 & 13,5 & 22,3 \\
\hline & $96 \mathrm{~h}$ & 11,3 & 9,4 & 13,6 \\
\hline \multirow[t]{4}{*}{ Clone 5} & $24 \mathrm{~h}$ & 10,4 & 6,3 & 17,2 \\
\hline & $48 \mathrm{~h}$ & 9,6 & 7,6 & 12,2 \\
\hline & $72 \mathrm{~h}$ & 2,7 & 2,5 & 2,9 \\
\hline & $96 \mathrm{~h}$ & 0,8 & 0,8 & 0,9 \\
\hline \multirow[t]{4}{*}{ Clone 10} & $24 \mathrm{~h}$ & 171,5 & 91,9 & 320,0 \\
\hline & $48 \mathrm{~h}$ & 105,6 & 65,8 & 169,6 \\
\hline & $72 \mathrm{~h}$ & 42,9 & 22,9 & 80,4 \\
\hline & $96 \mathrm{~h}$ & 8,5 & 2,6 & 28,2 \\
\hline
\end{tabular}

${ }^{\mathrm{a}} \mathrm{pM}$ concentrations of riproximin.

In comparison to the other clones, the ASML-clone 10 showed a clear and prolonged stimulation (up to 23\%) at low Rpx concentrations (0.1-3.3 pM). In addition to this observation, the high IC 50 values, ranging from $172 \mathrm{pM}(24 \mathrm{~h})$ to $9 \mathrm{pM}$ (96 h) indicate a low sensitivity of clone 10 to Rpx, Fig. 1D. Nevertheless, there was a 20 fold difference between the highest and lowest IC50 values.

Western blot analysis. After exposing ASML cells to various concentrations of riproximin, selected apoptosis related proteins were investigated by western blot analysis (Fig. 2). After 48 h, caspases 8, 9 and 3 were upregulated and activated at concentrations ranging from 10-100 pM. The upregulation varied concentration dependently from 0 to 1.3 fold (caspase-3), 1.6 to 1.8 fold (caspase-8), and 2.5 to 1.7 fold (caspase-9). In addition, the activation of caspases was shown by the fragmentation of pro-caspases to the active caspase. Furthermore, ATF3 was upupregulated to a slightly increased plateau following all concentrations used (1.1 to 1.7 fold).

Response of tumor bearing nude rats to treatment. Control nude rats showed a mean survival time of 17 days (Table II). At necropsy, a mean liver weight of $22 \mathrm{~g}$ was found, as well as a positive body weight development. Per-oral administration of riproximin $(3.4 \mu \mathrm{g} / \mathrm{kg}$, group $1 \mathrm{~b}$, Table II) was not associated with a positive therapy effect; i.v. administration of this dose, however, was highly effective, but caused toxicity leading to premature death of the animals. Therefore, a reduced dose of riproximin was used subsequently via the intravenous route $(1.7 \mu \mathrm{g} / \mathrm{kg}$, group $2 \mathrm{~b})$, which prolonged the live span of tumor 
Table III. Response of ASML-PDAC tumor bearing nude rats to treatment.

\begin{tabular}{|c|c|c|c|c|c|c|c|c|c|}
\hline Trial & $\begin{array}{c}\text { Group } \\
\text { no. }\end{array}$ & $\begin{array}{c}\text { Mean } \\
\text { survival } \\
\text { (days) }\end{array}$ & $\mathrm{P}$-value & $\begin{array}{l}\text { Body weight } \\
\text { start of } \\
\text { treatment }(\mathrm{g})\end{array}$ & $\begin{array}{l}\text { Body weight } \\
\text { end of } \\
\text { treatment }(\mathrm{g})\end{array}$ & $\begin{array}{c}\text { Mean Liver } \\
\text { weight }(\mathrm{g})\end{array}$ & P-value & $\begin{array}{l}\text { Mortality } \\
\text { (3 weeks) }\end{array}$ & $\begin{array}{c}\text { Light } \\
\text { emission }\end{array}$ \\
\hline \multirow[t]{3}{*}{1} & $1 \mathrm{a}$ & 16.5 & - & 219.8 & 248.6 & 22 & - & 100 & \\
\hline & $1 b$ & 16 & - & 221.7 & 241 & 20 & - & 67 & \\
\hline & $1 \mathrm{c}$ & 12 & tox. ${ }^{a}$ & 220 & 223.4 & 7.67 & tox. ${ }^{a}$ & 100 & \\
\hline \multirow[t]{4}{*}{2} & $2 \mathrm{a}$ & 17 & - & 222 & 254.2 & 20.98 & - & 87.5 & \\
\hline & $2 b$ & 20 & $-/++b$ & 221 & 249.7 & 10.18 & $+/++{ }^{b}$ & 20 & + \\
\hline & $2 c$ & 14.8 & - & 219 & 234.2 & 18.16 & - & 60 & - \\
\hline & $2 d$ & 15 & - & 201.4 & 220 & 16.88 & - & 40 & + \\
\hline \multirow[t]{6}{*}{3} & $3 a$ & 17.6 & & 203.5 & 233 & 21.78 & & 100 & \\
\hline & $3 b$ & 10.2 & tox. & 210.4 & 211 & 5.7 & tox. & 100 & \\
\hline & $3 c$ & 12 & tox. & 212.4 & 220 & 7.58 & tox. & 60 & \\
\hline & $3 d$ & 21.8 & $+/+{ }^{b}$ & 215.4 & 243 & 9.36 & - & 0 & + \\
\hline & $3 e$ & 20 & - & 225.2 & 232 & 9.92 & - & 20 & - \\
\hline & $3 \mathrm{f}$ & 19.4 & - & 200 & 215 & 7.88 & + & 20 & - \\
\hline
\end{tabular}

$++=\mathrm{P}<0.01,+=\mathrm{P}<0.05,-=\mathrm{P}>0.05,{ }^{\mathrm{a}}=$ toxic,${ }^{\mathrm{b}}=$ bilateral/unilateral group comparison.
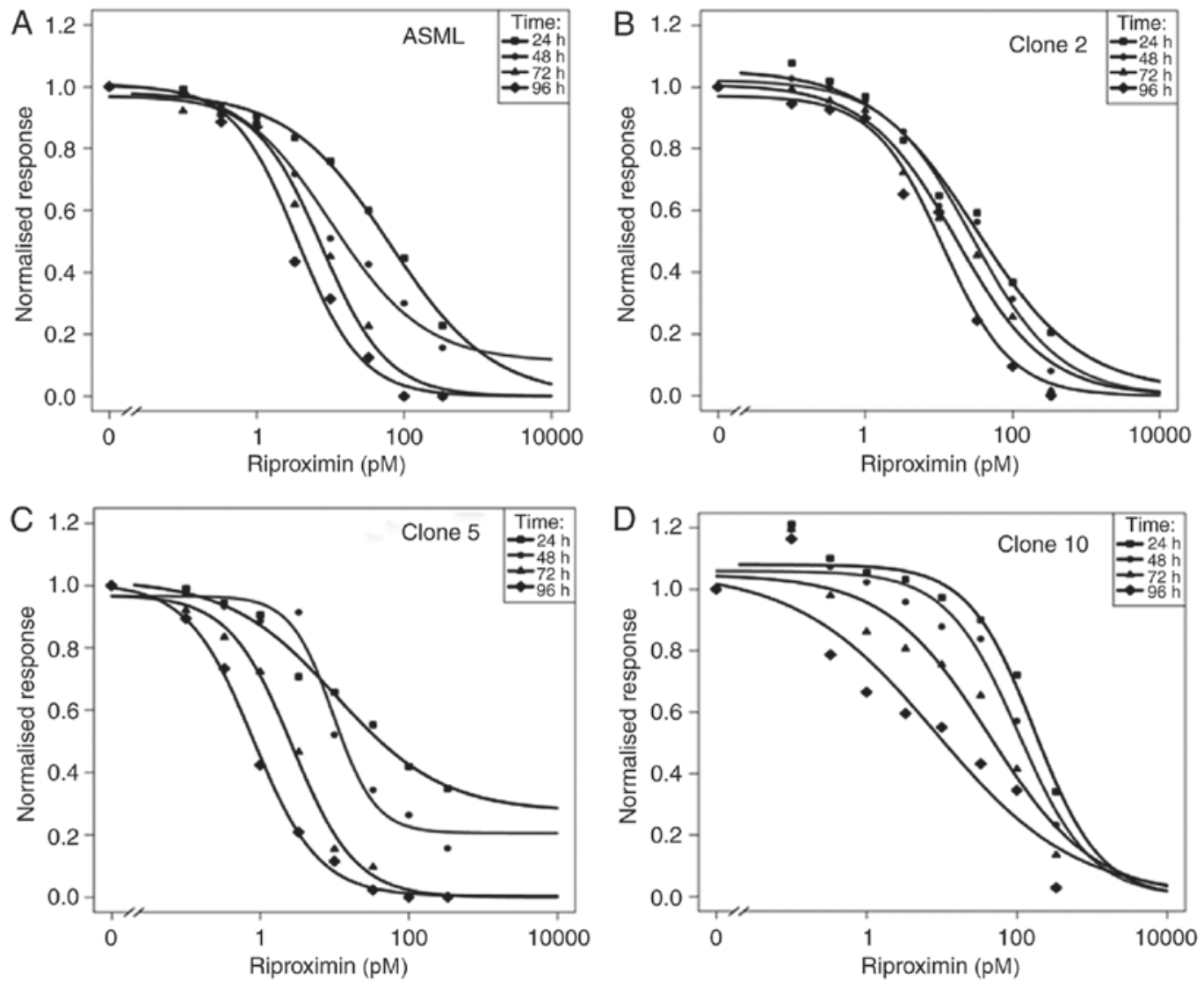

Figure 1. Cell growth inhibition of ASML cells and three ASML derived clones after exposure to riproximin. The $\mathrm{x}$ axis shows the Rpx concentration in $\mathrm{pM}$, the $y$ axis gives the response of living cells as determined by MTT assay, normalized to the respective control (1.0). All cells were incubated for $24,48,72$ and $96 \mathrm{~h}$ and exposed to a range of riproximin concentrations (0.1 to $333 \mathrm{pM}$ ). Each concentration was tested with eight replicates. (A) ASML cells, (B) clone 2 cells, (C) clone 5 cells, (D) clone 10 cells.

bearing animals by $18 \%$ and reduced the liver weight to $10.2 \mathrm{~g}$ $(\mathrm{P}<0.01$, respectively).
Treatment with dinaline, alone or in addition with riproximin was less effective. Surprisingly, the antineoplastic effect 


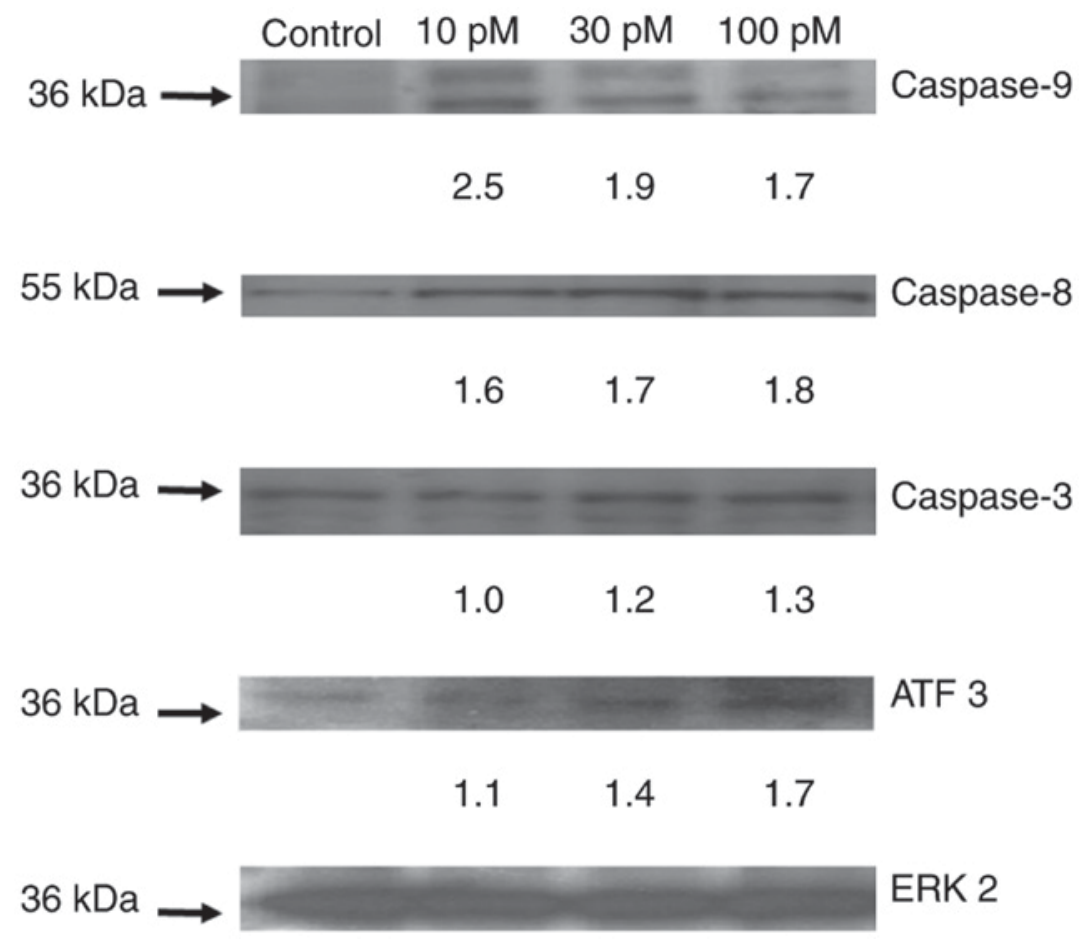

Figure 2. Immunoblot analysis of ASML cells after $48 \mathrm{~h}$ exposure to various concentrations of Rpx. Protein lysates were probed for caspases 8,9 and 3 as well as for ATF3. ERK-2 served as loading control. The number below the individual bands shows the expression in relation to the respective control.
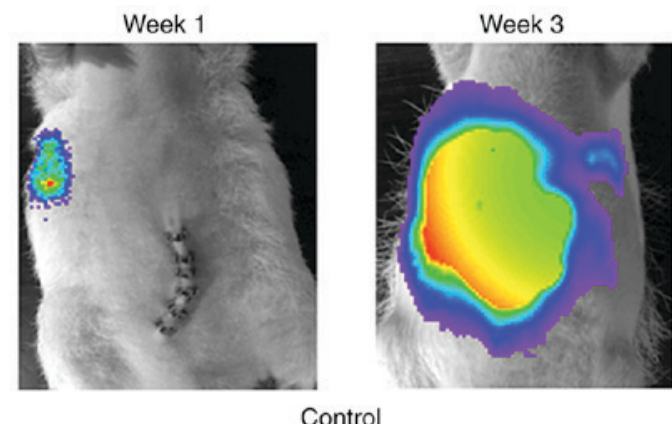

Control

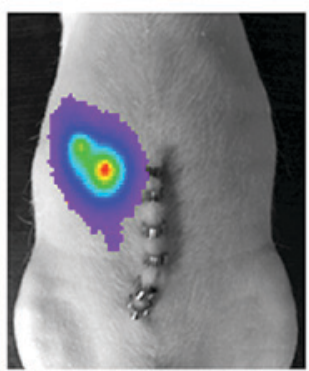

Riproximin, $1.7 \mu \mathrm{g} / \mathrm{kg}$
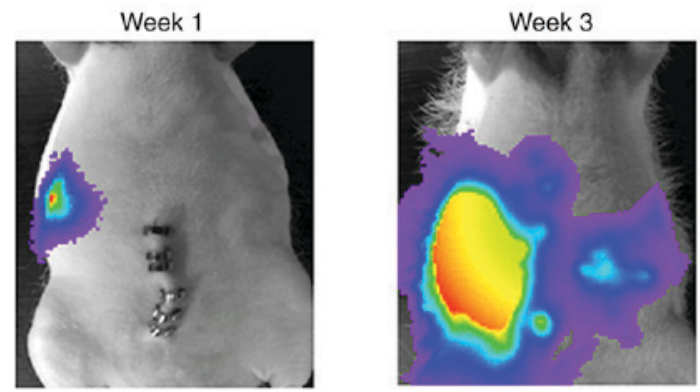

Gemcitabine, $50 \mathrm{mg} / \mathrm{kg}$
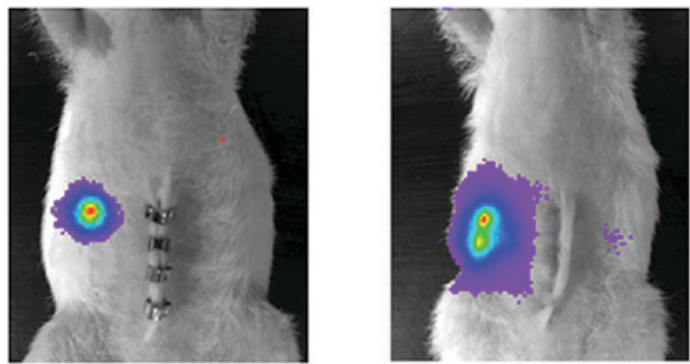

Riproximin, $3.4 \mu \mathrm{g} / \mathrm{kg}$

Figure 3. Detection of ASML cells growing in the liver of nude rats after intra-portal implantation by bioluminescence imaging after one and three weeks, respectively. The light emission was based on luciferase activity of ASML ${ }^{\text {GFP-LUC }}$. The rats were treated either with Rpx $(1.7 \mathrm{or} 3.4 \mu \mathrm{g} / \mathrm{kg}) \mathrm{or}$ with GEM $(50 \mathrm{mg} / \mathrm{kg})$.

of riproximin, as shown by the mean liver weight, was reduced by co-treatment with dinaline. The significant antineoplastic effect of riproximin against ASML cells growing in the liver of nude rats was confirmed in the 3rd experiment. Treatment with $1.7 \mu \mathrm{g} / \mathrm{kg} \mathrm{Rpx}$ administered intra-peritoneally prolonged the lifespan of tumor bearing animals and reduced the tumor weight by $90 \%$ to an almost normal liver weight $(\mathrm{P}<0.01$, respectively).
Treatment with gemcitabine was almost equally effective as treatment with riproximin (groups 3d and e, Table III and Fig. 3), but combination of these drugs was only minimally more active than the single agents, as shown by a mean liver weight of $7,9 \mathrm{~g}$ (combination) vs. 9,4 g (riproximin) and $9.9 \mathrm{~g}$ (gemcitabine).

Light emission recorded at the terminal stage of the animals, paralleled the tumor mass growing in the rat livers and the 

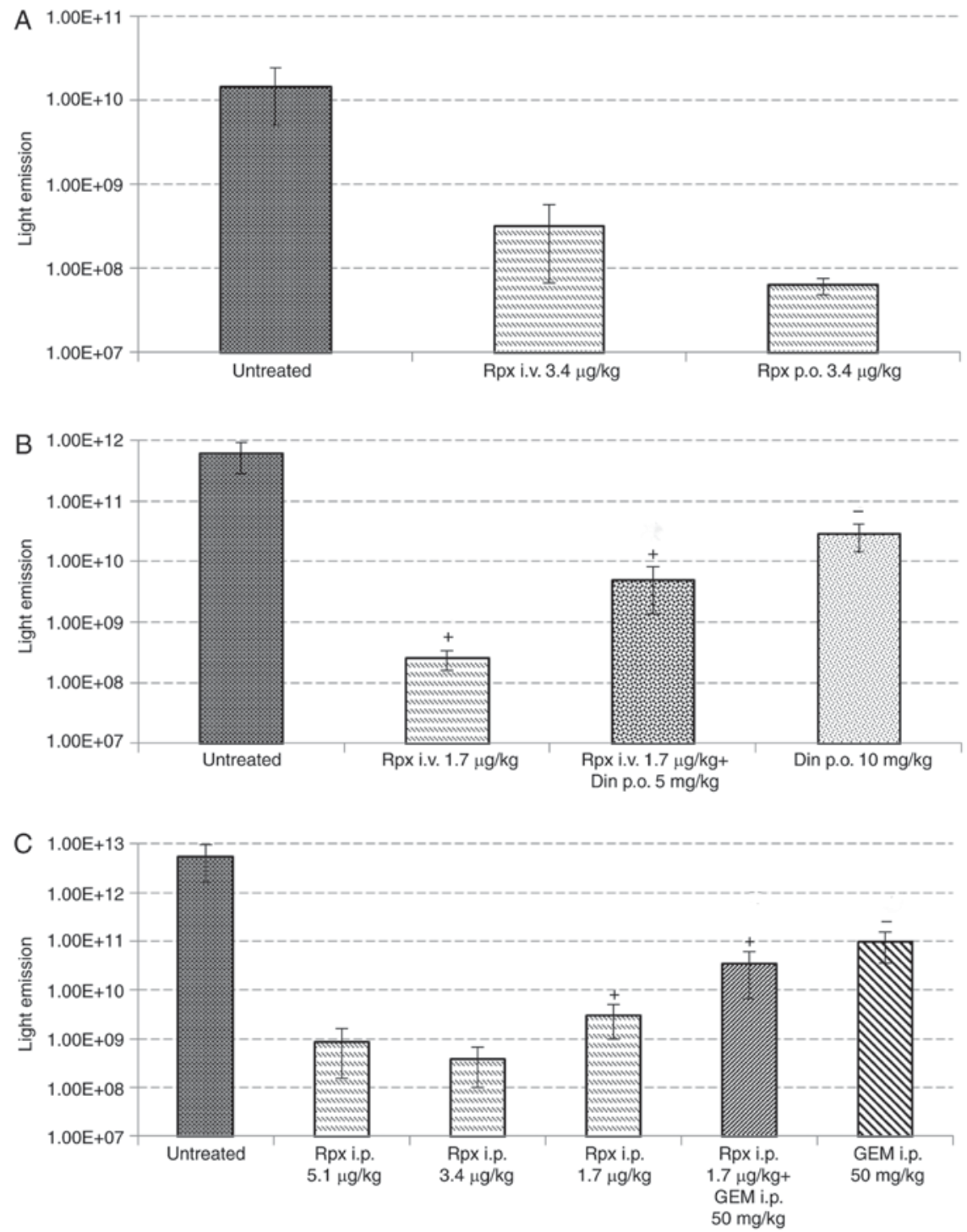

Figure 4. Antineoplastic activity of riproximin, dinaline and gemcitabine therapy on ASML rat liver metastasis in response to single or combined administration. (A) Antineoplastic activity of Rpx. Rpx therapy was administered at a dose of $3.4 \mu \mathrm{g} / \mathrm{kg}$ animal weight on days one, two and three for one week, either perorally or intravenously. The detected light emission of the respective group is shown as mean with standard deviation. (B) Antineoplastic activity of Rpx and/or dinaline Therapy. The therapy was performed with Rpx at a dose of $1.7 \mu \mathrm{g} / \mathrm{kg}$ intravenously three times a day each second day for two weeks or with dinalin at a dose of $10 \mathrm{mg} / \mathrm{kg}$ perorally once daily for 10 days or with the combination of Rpx $1.7 \mu \mathrm{g} / \mathrm{kg}$ i.v. (three times a day each second day for two weeks) plus dinaline $5 \mathrm{mg} / \mathrm{kg}$ p.o. (once a day for 10 days). (C) Antineoplastic activity of Rpx and/or gemcitabine therapy. The therapy with Rpx was administred intraperitoneally at doses of 5.1,3.4 or $1.7 \mu \mathrm{g} / \mathrm{kg}$ animal weight every second day for 20 days or with gemcitabine at a dose of $50 \mathrm{mg} / \mathrm{kg}$ animal weight intraperitoneally once weekly for two weeks or with $1.7 \mu \mathrm{g} / \mathrm{kg}$ i.p.Rpx (every other day for 20 days) plus $50 \mathrm{mg} / \mathrm{kg}$ i.p. gemcitabine (once a week for 2 weeks). The detected light emission of the respective group is shown as mean with standard deviation. +, significant therapeutic effect: $\mathrm{P}<0.05$; -, no therapeutic significant effect; no symbol, the effect was toxic and it has no therapeutic relevance. Rpx, riproximin.

animals' survival time. However, treatment with Gem, although effective in reducing the liver weight significantly and extending the life span of treated rats, was related to a distinctly higher light emission than that observed following treatment with riproximin or the combination of Rpx with Gem (Fig. 4).

\section{Discussion}

This is the first report on the activity of Rpx in rat ASML pancreatic cancer cells in vitro and in vivo. PDAC is a malignancy with low sensitivity to current antineoplastic drugs (2). As a consequence, the investigation of new drugs with activity in this disease is of high potential interest. Rpx has fulfilled this criteria as it showed high antiproliferative activity in ASML mother cells as well as in three cell clones derived thereof. Interestingly, there was a relatively high variation in sensitivity to Rpx between the three ASML clones as the IC50 values obtained after $24 \mathrm{~h}$ ranged from 17 fold from 172 to $10 \mathrm{pM}$. An even larger variation in sensitivity had been observed before in cell lines derived from different tissues of origin (13), with the respective IC50 values differing by a factor of 100. It is plausible to speculate that these differences may depend on the cells' affinity to Rpx, which affects its binding and uptake. Recently, the affinity of riproximin to certain sugar moieties has been investigated (15). Riproximin was shown to bind with a high affinity to certain types of glyco-structures in a carbohydrate microarray, namely to bi- and tri-antennary complex $\mathrm{N}$-glycan structures (NA2/NA3) and to repetitive 
$\mathrm{N}$-acetyl-D-galactosamine (GalNAc), the so-called clustered $\mathrm{Tn}$ antigen, a cancer-specific O-glycan on mucins (15). Future experiments will be related to the presence of these structures on ASML cells to possibly relate their sensitivity to the respective presence of these glyco-structures.

Another reason for variances in sensitivity could be differences in proliferation rates between the ASML cell clones. It is generally assumed that cancer cell sensitivity against cytostatics is correlated with their proliferation rate (17). In line with this notion the ASML clone 5, having the shortest tumor cell doubling time, was most sensitive to Rpx. This clone showed the lowest IC50 values after 24 to $96 \mathrm{~h}$, respectively, and did not show any stimulation at low concentrations of Rpx. The mother cell line and clone 10 , on the other hand, were less sensitive, but showed an about 20-fold reduction of initial IC50 values after four days of continuous incubation. This indicates that the exposure to Rpx can cause not only early but also late events leading to cell death.

The activity of Rpx in vivo against pancreatic cancer liver metastasis was a main finding of the present study and is related to the high anti-proliferative activity against ASML cells in vitro. Regarding the liver as metastasis site, it is of interest that Rpx showed also high antineoplastic activity in a rat colorectal cancer liver metastasis model in vivo (13). The efficacy observed in this study was only slightly better than that of gemcitabine, when the liver weight was considered. However, the liver weight as indicator of remnant tumor mass differed significantly from control, whereas that following exposure to gemcitabine did not. In addition, the light emission following both treatment groups showed that distinctly less tumor cells survived after exposure to Rpx than after Gem. This indicates that Rpx killed the ASML tumor cells more specifically than Gem. The combination of Rpx with GEM did not improve the activity of Rpx, the combination with DIN even thwarted the activity of Rpx. The reason(s) why the activity of Rpx is reduced by an HDAC-inhibitor like DIN remain unclear.

Rpx is a new plant lectin, which was classified as a RIP of type II that was isolated from the plant Ximenia americana. Its antineoplastic activity was recently demonstrated in several studies from our group $(13,14)$. It is noteworthy that the combination of Rpx with either GEM or DIN did not result in a further benefit for the survival of liver metastases bearing animals, in spite of a further reduction in mean tumor weight as compared to the respective monotherapy. Thus, the search for suited combination partners will be continued in future experiments.

As for other RIPs of type II, the antineoplastic effect of Rpx is based on its ribosome inactivating property (14). From the immunoblot analyses of this study, clearly the apoptotic effect of Rpx was one of the reasons for cell death in ASML pancreatic cancer cells and the observed antineoplastic activity. In a previous study, we have shown that the apoptotic property of Rpx was based on the induction of endoplasmic reticulum stress (14). These results were confirmed in this study as demonstrated by the reduction of ATF3 levels after exposing ASML cells to Rpx. In addition, downstream of this pathway, apoptosis was induced by activation of caspases 3,8 and 9 .

In summary, Rpx inhibited ASML cell proliferation at low, $\mathrm{pM}$ concentrations, caused apoptosis and reduced tumor growth significantly by $90 \%(\mathrm{P}<0.05)$. Concomitantly, the survival rate of rats was significantly increased $(\mathrm{P}=0.05)$. Higher doses of Rpx caused no further reduction in tumor size when compared to the low dose of Rpx or a combination of Rpx with GEM or DIN. The results suggest that Rpx has a clear potential for use in pancreatic cancer treatment. Further experiments are required for elucidating its affinity for certain cancer cells and optimizing the combination therapy with other antineoplastic agents.

\section{References}

1. Jemal A, Siegel R, Xu J and Ward E: Cancer statistics, 2010. CA Cancer J Clin 60: 277-300, 2010

2. Burris HA IIIrd, Moore MJ, Andersen J, Green MR, Rothenberg ML, Modiano MR, Cripps MC, Portenoy RK, Storniolo AM, Tarassoff $\mathrm{P}$, et al: Improvements in survival and clinical benefit with gemcitabine as first-line therapy for patients with advanced pancreas cancer: A randomized trial. J Clin Oncol 15: 2403-2413, 1997.

3. Sant M, Allemani C, Santaquilani M, Knijn A, Marchesi F and Capocaccia R; EUROCARE Working Group: EUROCARE-4. Survival of cancer patients diagnosed in 1995-1999. Results and commentary. Eur J Cancer 45: 931-991, 2009.

4. Conroy T, Desseigne F, Ychou M, Bouché O, Guimbaud R, Bécouarn Y, Adenis A, Raoul JL, Gourgou-Bourgade S, de la Fouchardière C, et al: FOLFIRINOX versus gemcitabine for metastatic pancreatic cancer. N Engl J Med 364: 1817-1825, 2011.

5. Demols A, Peeters M, Polus M, Marechal R, Gay F, Monsaert E, Hendlisz A and Van Laethem JL: Gemcitabine and oxaliplatin (GEMOX) in gemcitabine refractory advanced pancreatic adenocarcinoma: A phase II study. Br J Cancer 94: 481-485, 2006.

6. Von Hoff DD, Ervin T, Arena FP, Chiorean EG, Infante J, Moore M, Seay T, Tjulandin SA, Ma WW, Saleh MN, et al: Increased survival in pancreatic cancer with nab-paclitaxel plus gemcitabine. N Engl J Med 369: 1691-1703, 2013.

7. Kim SK, Kim H, Lee DH, Kim TS, Kim T, Chung C, Koh GY, Kim H and Lim DS: Reversing the intractable nature of pancreatic cancer by selectively targeting aldh-high, therapy-resistant cancer cells. PLoS One 8: e78130, 2013.

8. Herrera L, Bostrom B, Gore L, Sandler E, Lew G, Schlegel PG, Aquino V, Ghetie V, Vitetta ES and Schindler J: A phase 1 study of Combotox in pediatric patients with refractory B-lineage acute lymphoblastic leukemia. J Pediatr Hematol Oncol 31: 936-941, 2009.

9. Stirpe F and Battelli MG: Ribosome-inactivating proteins: Progress and problems. Cell Mol Life Sci 63: 1850-1866, 2006.

10. Lin JY, Tserng KY, Chen CC, Lin LT and Tung TC: Abrin and ricin: New anti-tumour substances. Nature 227: 292-293, 1970.

11. Zwierzina H, Bergmann L, Fiebig H, Aamdal S, Schöffski P, Witthohn $\mathrm{K}$ and Lentzen $\mathrm{H}$ : The preclinical and clinical activity of aviscumine: A potential anticancer drug. Eur J Cancer 47: 1450-1457, 2011.

12. Voss C, Eyol E and Berger MR: Identification of potent anticancer activity in Ximenia americana aqueous extracts used by African traditional medicine. Toxicol Appl Pharmacol 211: $177-187,2006$.

13. Voss C, Eyol E, Frank M, von der Lieth CW and Berger MR: Identification and characterization of riproximin, a new type II ribosome-inactivating protein with antineoplastic activity from Ximenia americana. FASEB J 20: 1194-1196, 2006.

14. Horrix C, Raviv Z, Flescher E, Voss C and Berger MR: Plant ribosome-inactivating proteins type II induce the unfolded protein response in human cancer cells. Cell Mol Life Sci 68: 1269-1281, 2011.

15. Bayer H, Essig K, Stanzel S, Frank M, Gildersleeve JC, Berger MR and Voss C: Evaluation of riproximin binding properties reveals a novel mechanism for cellular targeting. J Biol Chem 287: 35873-35886, 2012.

16. Eyol E, Murtaga A, Zhivkova-Galunska M, Georges R, Zepp M, Djandji D, Kleeff J, Berger MR and Adwan H: Few genes are associated with the capability of pancreatic ductal adenocarcinoma cells to grow in the liver of nude rats. Once Rep 28: 2177-2187, 2012.

17. Corrie PG: Cytotoxic chemotherapy: Clinical aspects. Medicine 36: 24-28, 2008.

This work is licensed under a Creative Commons Attribution-NonCommercial-NoDerivatives 4.0 International (CC BY-NC-ND 4.0) License. 